the curves are in each case all but straight, and are nearly parallel to the vertical. They show (I) that the skull of the living Englishman, that is to say, of the Royal Engineers, is a little narrower than that of the seventeenthcentury Londoner, the difference being greatest across the ears, and that, in like manner, the skull of the Batetelu Negro is a little broader than that of the Negro from Fernando Vas. In both cases the general similarity, or identity of type, between the two skulls under comparison is clearly brought out.

Lastly, we may use the method to compare the left side of the skull with the right. And so we find (Fig. 5) that

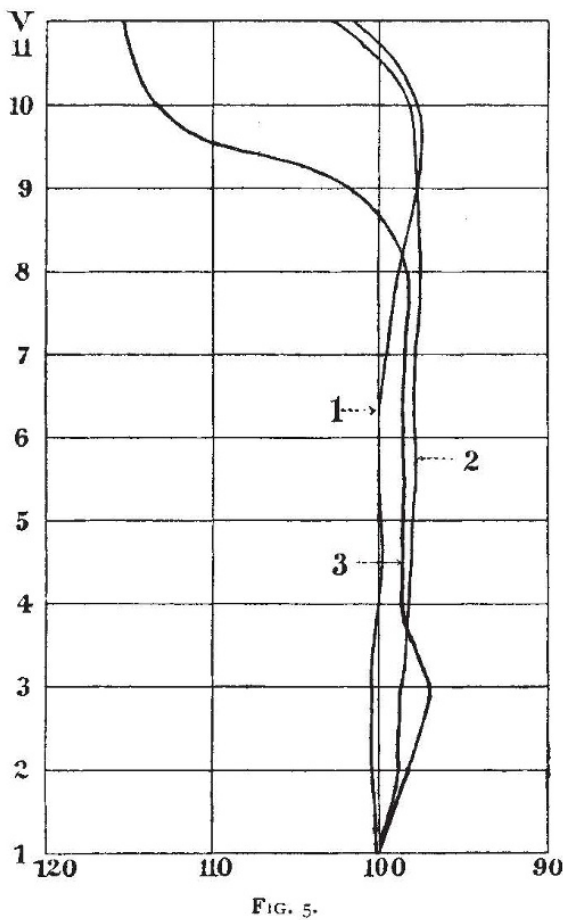

in the English skull there is approximate identity throughout most of the section, the left side being narrower in the upper portion only; in the Negro (Fernando Vas) the left side is throughout inferior, while the Cro-magnon skull is markedly unsymmetrical, the left side being the narrower below, but expanded or flattened above in a striking degree. January 27 . D'Arcy W. ThoMpson.

\section{Microscope Stands,}

THE correspondence which has ensued on the interesting article on the above subject which appeared in NATURE of December 21 , I9II, has afforded much material for reflection. There must be a best possible design for a microscope stand, but it is evident that the one required by the expert amateur is different from that which is acceptable and advantageous to the professional in the laboratory. The former demands, and can wit advantage utilise, many refinements that never appeal to the latter. The best English microscopes undoubtedly supply the needs of the expert-that appears to be admitted-and assuming that the design of the Continental instrument is preferred in the laboratory, it might be that the worker would derive fuller benefit from his microscope if only some additional conveniences were at his disposal and he knew how to use them.

So far, the correspondence has been contributed by experienced technical microscopists; but the views of the other side would be welcome and informing.

To revert to the, article in question, no one who has had the use of a centring substage would be disposed to accept a centring adjustment to the nosepiece in preferNO. 2207 , VOL. 88$]$ ence. It is stated that the latter adjustment is provided in the Continental models, but I am unable to find a centring nosepiece listed or described in either of the catalogues of the two leading German manufacturers of microscopes, excepting only in connection with petrological microscopes. Some centring device is admitted to be necessary, and continual working with condensers having large aplanatic cones soon reveals the necessity for the centring substage.

It is suggested that the correction collar fitted to objectives is superior to the rackwork draw-tube for adjusting for varying thicknesses of cover glasses. This is quite correct; but probably not more than $\mathbf{I}$ per cent. of the objectives that are sold have correction collars, and in consequence of the perfection in which even students' lenses are now made, the sensitiveness to thickness of cover glass necessitates careful adjustment by variation of tube length. There is another important feature of the mechanical draw-tube, and that is it gives a maximum and a minimum body length which permits of the use of any objective, whether corrected for the short or the long tube, though this is subsidiary.

As to the standardisation of the substage fittings, a definite size is given by the Royal Microscopical Society, and if this is adhered to there can be very little trouble about interchanging. It has to be remembered that onethousandth of an inch in the diameter of a tube makes all the difference between a tight and a slack fitting; tube fittings are particularly liable to variation in consequence of slight bending. Objectives do not always interchange, though all are ostensibly made to the standard size; but the alterations needed are exceedingly slight, and the differences in the substage apparatus of standard size are rarely such as cannot be quickly corrected. It seems reasonable to assume that if it be good to have a standard size for eyepieces and objectives, it is equally advantageous to have one for the substage. The English makers work loyally to the one standard of the Royal Microscopical Society, while the Continental makers each have two or three different ones.

At the bottom of all questions relating to the use of the microscope is the urgent necessity for systematic teaching in the elementary technique of the instrument. It is not unusual to meet men of eminence who are constantly working with microscopes who do not even know that a substage condenser requires to be focussed. How is it possible that the refinements of the English microscope can appeal to their students?

F.R.M.S.

\section{The Inheritance of Mental Characters.}

To the discussion on the question of the inheritance of mental characters ( $v$. NATURE, December 28 , I9II, p. 278). as one who takes an interest in the subject, but can lay no claim to having expressly studied it, I should be glad to be allowed to contribute a few experiences.

In a girls' primary school the writer knew a child who from the age of five until eleven (when her education was complete) was, owing to her daring athletic feats, a torture to her teachers. They were in a perpetual worry lest she should break her bones or her neck. Punishment -and it was pretty liberal-was of no use; when their backs were turned she was at it again. They-and some of them were old teachers-had never met one like her. The other children, about ${ }^{5} 0$ in number, were normal. This one had no peculiar environment, no special opportunities. But her father was a professional showman. She, like the Greek CEdipus, had never seen him, nor did her mother ever speak of him. He had been " raised" on a small farm. His brothers were commonplace workmen. The teachers were unaware of the showman parentage. Some few of us knew, and watched with interest the developments.

This case seems an instance of the inheritance of an acquired taste.

True it no more than any case that can be brought forward, is not beyond question; for just possibly in the child-as very likely previously in the father-the mere abnormal potentiality was there. This perhaps some accident revealed to her. We aiways like to do what we 